\title{
MEMORIA, REESCRITURA, IDENTIDAD EN LOS CUENTOS GALLEGOS DE CARLOS MONTENEGRO
}

\author{
Por \\ L. MARTUL TOBÍO
}

\begin{abstract}
Mucho tiempo después de su infancia transcurrida en Galicia, Carlos Montenegro escribió algunos cuentos que recogen experiencias especialmente difíciles de esa edad. No desentonan en cuanto a la concepción básica con las otras piezas que completan sus libros, tanto en técnica como en conclusiones últimas. Pero algo hay que los diferencia, y es el reconocimiento de que los textos se han elaborado con exclusivo material autobiográfico, el cual alcanza una significación e implicaciones inusitadas.

De esta condición autobiográfica no nos interesa tanto comprobar aquí lo que hay de reproducción fiel de sus avatares infantiles, como la manera en que los ficcionalizó. No por constricción inevitable a unas exigencias propias de lo literario, más bien porque el intento de hablar de uno mismo con el deseo de decir algo verdadero implica necesariamente una ficcionalización. La afirmación de Lacan es bien conocida: la verdad tiene estructura de ficción.

El comienzo de estos cuentos, véase «El cordero»o «La escopeta», es una declaración o confesión que introduce un registro de autoanálisis confidencial que se mantiene vivo mediante la repetición de signos recordatorios a lo largo del relato. Desde el punto de vista estructural es una introducción que retrasa el comienzo de la acción única del cuento. Ella sirve también para que el relato se desenvuelva desde una posición de presente.
\end{abstract}

"CUADERNOS DE ESTUDIOS GALLEGOS", Tomo XLV, Fascículo 110, Santiago 1998. 
El narrador, que deja traslucir la voz autorial, es consciente de lo que ha llegado a ser pasados los años, de modo que toda la narración está determinada por su condición contemporánea. Es decir, cuenta el pasado desde la perspectiva de lo que es en la actualidad, sólo que para poder dar explicación de lo que es -razón de escribir-realiza este acto de memoria o de recuento del pasado. Por esto se dice que el narrador al conocer el desenlace interpretará los hechos según éste, de modo que lo narrado será visto en función de lo que aquél ha llegado a ser. Los sucesos, por tanto, se nos darán no en su pura sucesión sino incluidos en algún tipo de esquema interpretativo, a partir del cual lo que fueron para el niño situaciones desconectadas o carentes de significado o bien conectadas de manera diferente, ahora se articulan de acuerdo con la mentalidad del narrador en el momento de contar. De ahí que lo que puede aparecer en un principio como la posibilidad de transmitir unos hechos de manera directa y detallada, se nos revela sometido desde el comienzo mismo a la incertidumbre. No obstante, hay que tener presente que la causa que dio origen al cuento es la necesidad de hallar una explicación a unas experiencias vitales que el autor vivió de niño. Escribir el cuento viene a ser reescribir su identidad, reescripción que no implica una idea de identidad sustancial, por el contrario supone una identidad que está siendo reconstruida, incluso a partir de otros textos, puesto que en el cuento aparecen las opiniones de las criadas, por ejemplo, en el cuento «El cordero», lo cual nos permite comprender su diversidad constitutiva e inestable ${ }^{1}$.

La declaración que compone la introducción o primera secuencia del cuento puede leerse de acuerdo con las pautas convencionales de elaboración de una estructura cuentística. En «El cordero» se menciona el desenlace en los primeros renglones y se sirve de fórmulas de verosimilitud realista. Para sustentar su estrategia acude a una serie de conside-

\footnotetext{
' Para las categorías empleadas en este trabajo se pueden consultar las siguientes obras como bibliografía elemental: D. Bertaux, ed., Biography and Society, Beverly Hills, Calif., Sage, 1980; P.J. Eakin, Fictions in Autobiography, Princeton, Princeton University Press, 1985; Mark Freemanm, Rewriting the Self, London, Routledge, 1993; J. Schotter \& K.J. Gergen, eds., Texts of Identity, London, Sage, 1989; C. Taylor, Sources of the Self: The Making of the Modern Identity, Cambridge, Mass., Harvard University Press, 1989.
}

"CUADERNOS DE ESTUdiOS GALLEGOS", Tomo XLV, Fascículo 110, Santiago 1998. 
raciones sobre la memoria que viene a legitimar el que los sucesos estén recogidos con precisión documental. No obstante, lo que resulta sintomático es su deslinde entre recuerdos fieles y «desfigurados» que pone de manifiesto, por un lado, la postura objetivista-realista asumida teóricamente, pero por otro es indicativo de que en la historia de su vida, que él narrativiza, hay hechos que su memoria ha transformado o reelaborado subjetivamente, y la expresión utilizada recuerdos que han adquirido «sabor de leyenda» delata su condición ficcional: «Muchos hechos de aquella época se han borrado de mi mente; muchos, casi todos; los que no, se han ido opacando; mejor dicho, desfigurándose, cobrando sabor a leyenda.»

Se apartan los recuerdos por su imposibilidad de recuperarlos detalladamente, al tiempo que se reconoce la inevitable actuación de lo subjetivo en todo recuento de experiencias vividas. Es evidente que en esas palabras se busca el contraste para destacar la objetividad de los recuerdos que quiere contar. Lo que no debe pasar desapercibido es que unos avatares que tanto lo impresionaron tienen que estar más intensamente marcados por elaboraciones subjetivas que otros más ocasionales. Precisamente si cuenta ese recuerdo es porque se le impone: «A pesar de los años transcurridos y de los múltiples sucesos que me han ocurrido en estos años, no he logrado olvidar el fin de aquel cordero que, siendo yo niño aún, me regalo mi padre. No lo he olvidado ni lo podré olvidar jamás». Su persistencia a lo largo de la vida de quien cuenta desemboca ahora en el necesario recuento y reescritura, porque precisamente gracias a que es escrito puede producir una explicación que le va a permitir conocerse mejor a sí mismo y a su realidad.

Por lo anteriormente dicho, debemos tener en cuenta dos procesos de fidelidad rememorativa diferentes al aproximarnos a los textos de Montenegro. Uno empírico y otro interpretativo. El primero, asentado en la orientación social-realista de su estética, es el origen de su pretensión mimética de los hechos; el segundo, anclado en la índole misma de la rememoración, conduce a las reinterpretaciones del pasado, a las invenciones subjetivas. Ambos procesos, al superponerse, desdoblan el significado de los procedinmientos técnicos de repertorio como, por ejemplo, las reseñadas cauciones de veracidad con que se inicia el cuento. Estas suelen identificarse como estrategias propias de verosimilitud realista, pero aquí cabe identificarlas como síntomas de la no reconocida inter- 
pretación subjetiva del relato. Inevitablemente, todo intento de dar razón de un pasado personal implica una interpretación, si se quiere decir algo valioso.

Pues bien, si el desenlace del cuento, la muerte brutal del cordero o también el conflicto recogido en «La escopeta», fue un trauma terrible para el niño, su relato estará marcado por la subjetividad y tendrá que tener un elevado grado de invención en su finalidad de darle un significado en el sentido de lo que luego fue la vida adulta del narrador-autor. De aquí también la manipulación a la que aludíamos cuando mencionábamos que el hecho de narrar desde el presente-final, conociendo el desenlace, incide sobre la interpretación de lo contado. La mentalidad de ese momento de contar está estableciendo un marco desde el que realizar conexiones y selecciones de datos.

En esta reescritura de la identidad Montenegro tuvo que cambiar las partes de una narración autobiográfica dado que el cuento no le permitía la extensión indefinida de otros géneros como la novela o la autobiografía. La continuidad de episodios se ve rectificada, en este caso, por las imposiciones propias del género cuento, selección, concentración, simplificación. Pero este hecho no afecta a la índole fundamental de la narración misma, tomada como formulación discursiva de una historia vital con la finalidad de redefinir la identidad del narrador. El cuento jerarquiza los acontecimientos a partir del desenlace, pero no es un cierre absoluto porque la función de las consideraciones iniciales es precisamente situar ese episodio central y los que le acompañan en una línea continuada de sucesos que, es verdad que no están recogidos en el cuento, pero que la palabra del narrador hace presentes.

En consecuencia, adoptando las categorías elaboradas por Mark Freeman (1993), encontramos la primera fase, llamada «reconocimiento», en las referencias más elementales sobre las circunstancias de tiempo y lugar, acompañadas de sus primeros comentarios sobre su identidad; la segunda fase de distanciamiento e identificación provisoria de la situación del protagonista infantil que tiene escaso desarrollo pero que permite aclarar o precisar lo que el niño vivió elementalmente; las dos últimas etapas, de la articulación y de la apropiación, que corresponden al orden del narrador, niño hecho adulto, y vienen a ser el producto del largo período vital silenciado, no incluido en el texto, a no ser por las implicaciones de los comentarios y perspectiva del narrador. La acción del cuento como 
resultado de los procedimientos de concentración describe un período que se cierra sin alcanzar la apropiación.

La acción de «El cordero» comienza en la segunda secuencia con un signo muy representativo «Fue en mi país natal». La forma verbal, la referencia al tiempo y lugar repiten un procedimiento de larga tradición. No obstante, el desarrollo de la acción se detiene para dar paso a distintas consideraciones que deben ser incluidas en el orden de una problemática interpretativa. Estas dos consideraciones introducen la duda respecto a su objetividad documental porque el narrador ha preferido saltar al presente e informar de cómo está determinado en su conciencia por lo que va a narrar. El proceso de reescritura del pasado se hace desde una circunstancia última conflictiva y en relación al resultado en el que desembocaron esas experiencias anteriores. De ser consecuente con la proclamada voluntad objetivista el narrador debería haber descrito desde una posición interna al tiempo de los sucesos, exactamente de la manera aséptica con que lo realiza una crónica. El vaivén entre pasado y presente no tiene discusión y la incertidumbre sobre lo que es recogido o inventado-interpretado se hace mayor. Lo que el narrador dice es: « Fue en mi país natal, que a veces evoco con una tristeza enfermiza que es dulzura, saudade; y otras con un dolor agrio, inquinoso; con una malquerencia (...)». En el cuento «La escopeta» tenemos otro buen ejemplo de estrategias de verosimilitud y, al mismo tiempo, evidencia de una conciencia remodeladora: «Me parece que me iba a incensar, a sincerarme. Estoy en un lugar en donde hay muchos malhechores, y todos, aun los más cínicos, no hacen más que eso: sincerarse. Después se niegan. No. Nada de teorías; son de goma, se estiran, no prueban nada. Y un hecho es un hecho (...)». Aquí la reivindicación de lo puramente factual está en contradicción con todo lo que se narra en el cuento, si bien está presente un aspecto de la ideología del autor que tiene que ver con su idea de hombre, que más adelante precisaremos y que es importante, porque configura lo que se conoce como autor implícito.

La lógica argumentativa, por tanto, es algo elaborado posteriormente por un narrador adulto que va articulando los hechos y vicisitudes en función de un determinado modelo interpretativo y con la finalidad de explicar acontecimientos puntuales que han afectado a su vida. En esa hilera de situaciones del pasado ha elegido uno especialmente traumático que será, ahora en la escritura, donde le va a dar un sentido, algo que como niño y en 
edades posteriores se le resistió, de ahí las repetidas rememoraciones que confiesa haber tenido al comenzar el relato en «El cordero» o en el énfasis de «La escopeta».

La postura estética social-realista de Montenegro está en consonancia con una postura comprometida ideológicamente, baste recordar su militancia política y su presencia en la España republicana durante la guerra civil, sobre la que escribió alguna obra. El narrador de los cuentos gallegos relata desde un modelo de pensamiento progresista y de reivindicaciones sociales que estaba vinculado a una visión de la sociedad cuyo eje era una teoría de las estructuras socioeconómicas, completada por una concepción de la historia que situaba en su final una sociedad nueva. El ideal de hombre se identificaba con el representante de las clases populares, definido por sus sufrimientos, su entereza ante la adversidad y capacidad para superarlos. Por todo ello, los cuentos poseen una consciente orientación de compromiso moral e ideológico. Es esta postura de base la que hay que tener presente para comprender la interpretación del pasado en los cuentos, ya que es la responsable de que se dé una configuración muy concreta al conflicto que enfrenta al protagonista infantil con la realidad social. Incluso en alguno, como «La huella de cacique», el sesgo ideológico-político es manifiesto. La sociedad gallega se describe en conjunto opuesta al concepto de naturaleza por la disparidad de sus significados. Para realizar esa descripción el autor parte de la idea de estructura de dominio, identificable por la alianza del poder económico y de la Iglesia católica. Ambos se sirven de la religión como intrumento de cohesión y control. A Póboa do Caramiñal aparece dibujada como una sociedad tradicional, sumida en el atraso y cuya vida se halla circunscrita al dualismo de poderosos y débiles. Es desde una actitud de denuncia de la opresión y del orden establecido, fuente de los sufrimientos del individuo, cómo se narran las historias infantiles de Galicia. De hecho Montenegro estaba respondiendo a una corriente narrativa que se extendía por toda América Latina y que iba a cuajar en múltiples soluciones, desde el indigenismo a las demás variantes de la novela criollista.

Este enfoque social explica la interpretación de la vida del niño y su conflicto con los representantes de grupos sociales; es también la causa de la amplia presencia de interpretaciones sobre la significación de la mentalidad y conductas sociales de los personajes, incluidos sus padres. Preci- 
samente el protagonista está definido por un rechazo de las pautas de conducta establecidas o por la manera crítica con que las vive. Su identidad se encuentra en ese tiempo en fase de definición y especialmente se está haciendo en confrontación con contenidos sociales establecidos, volcado hacia su interioridad. Lo que se refleja en la acción es la soledad del protagonista: la muerte reciente de la madre, el padre alejado en frecuentes y prolongados viajes, las hermanas estudiando o veraneando en Villagarcía. Ante la ausencia de significados se comprende que acepte los juicios de las criadas o tome la decisión de tener un cordero. El vacío vital o ausencia de una subjetividad, que sólo de manera inmediata o espontánea se puede contrarrestar gracias a la relación afectiva con el cordero, va a ser reinterpretada por el narrador en el presente de la narración, para darle sentido a un tiempo que careció de él. En esto se halla la causa de la angustia del niño y de tiempos posteriores. El narrador escribe para solventar su angustia, causada por una falta de sentido que ejemplarmente se manifiesta en el desenlace con el desmayo -que es una pérdida de sentido-del protagonista infantil.

La macrosecuencia que se extiende en el cuento entre la introducción confesional y la serie de funciones que se anudan rápidamente desde el regalo del cordero hasta el desenlace, con la muerte del animal, viene a ser la puesta en acto del modelo interpretativo de la realidad social y el conflicto del protagonista infantil. En esta parte se da una definición de la sociedad en su conjunto, se precisan los roles de figuras como el maestro, el cura y la tía Pepiña, se recogen componentes ideológicos, y en especial se destaca la incidencia de la religión oficial católica y de las supersticiones; formas de conducta; relaciones de poder, etc. Es, con todo, una interpretación maniquea de la sociedad de A Póboa do Caramiñal. Para el narrador la villa se encuentra dividida de acuerdo con una concepción del bien y del mal interna al catolicismo: «La población se dividía en dos clases: blasfemos y místicos. Había dos templos, la iglesia y la taberna, a cual de los dos más sombrío. Allí Dios y el diablo tenían sus atribuciones fijas, marcadas (...)». Es una acción en gran medida preparatoria de la secuencia última, pero decisiva para que el narrador pueda alcanzar su objetivo.

También en esta segunda gran secuencia se vuelve a encontrar la oscilación entre memoria documental, promovida expresamente, y memoria interpretativa. La primera es la causante de la inclusión de cauciones de 
carácter verosímil con las que el narrador quiere asegurar que hechos y figuras se reproducen en detalle: «iQué bien me acuerdo de aquel maestro!» o «Aquella conversación que reconstruyo lo más fielmente posible (...)». La segunda hace que el conjunto de situaciones y personajes respondan a una perspectiva futura que elabora desde la madurez del narrador.

En el maestro, del cuento «El cordero» que estamos tomando como punto de referencia principal, es posible reconocer lo que hay de interpretación vinculada a una autobiografía, algo que no pertenece en exclusiva al orden de lo factual reproducido con pretensión objetiva. Los rasgos físicos aseguran la presencia directa, concreta, incluso se observa una mediación de lo que el niño pudo sentir en aquel tiempo ya que al apuntar el rasgo de «enorme» o «monstruoso», expresa el temor infantil. Junto a esto, el enjuiciamiento realizado desde el presente se manifiesta en el modelo interpretativo por el que la crueldad sin sentido, como rasgo definitorio del maestro, es parte del carácter de una sociedad atrasada socialmente, conservadora y degradada moralmente. El objetivo que se busca es, mediante la exposición y denuncia de la realidad establecida, la reclamación de una situación social más justa y progresista.

Al mismo tiempo las experiencias infantiles pueden ser interpretadas y no sólo descritas. Ahora se ofrecen las causas del odio, la tristeza, la malquerencia o la inquina. Son aspectos de la reescritura del ser del niño. La reelaboración del protagonista participa de ese modelo en otro presupuesto teórico, el de que el medio social objetivo configura las formas de conciencia del individuo. La escisión afectiva desde la que evoca expone que hay experiencias que son como marcas. Hay una continuidad, a ojos del narrador, entre la tristeza y sufrimiento del niño y la escisión anímica del presente narrativo. Aunque se afirme que hay una causalidad lineal de pasado a presente, en realidad, es tan importante la que va en sentido contrario.

En virtud del modelo de reinterpretación el narrador afirma que el medio social sórdido lo fue haciendo a su medida, volviéndolo malvado, egoísta, etc. Otras podrían ser las interpretaciones para estos hechos, pero precisamente la indefensión infantil, el que el protagonista careciese de la orientación interpretativa del narrador, queda probada en reacciones como la de decirle ingenuamente a su temida tía Pepiña que se hiciera bruja. El niño aparece escindido entre un medio que lo determina y una espontánea 
oposición interior. Hay algo en él que se sustrae a la determinación del medio, es la necesidad de afecto en una sociedad que «mide» el cariño. El narrador identifica dos reacciones que se enlazan a su presente: la relación con la naturaleza y la identificación con la madre. Pero para esto debemos revisar los signos que traicionan una vinculación más especial del autor con Galicia.

En un marco tan nítido de referentes y asunciones ideológicas como se da en su obra, lo biográfico, lo vital y la práctica literaria parecen signados por su condición comunicante. De ahí que estos cuentos que recogen experiencias infantiles se incluyan en el molde de los conflictos sociales con su valor de universalidad. Por el contrario no hay en Montenegro una sensibilidad suficiente para la cuestión nacional tal como se da en la península ibérica, aunque fue más receptivo para esa misma cuestión en los conflictos latinoamericanos. Con todo, es posible detectar incertidumbre en él a propósito de su origen y de sus experiencias infantiles, como la existencia de sus cuentos gallegos parece indicar. Es cierto que Montenegro se definía como cubano y en las escasas declaraciones que efectuó la referencia a Galicia sólo despunta de manera rápida, si bien no trivial. Tal vez la inveterada costumbre de los intelectuales latinoamericanos, tanto escritores como críticos, de insensibilidad e incomprensión del problema nacional en el Estado español haya contribuido a mantener el problema en la oscuridad.

Ya se sabe que en el puñado de cuentos localizados en Galicia, cinco en total, se emplea una perspectiva localizada en la distancia temporal y espacial de América. No obstante, sería difícil sostener que Montenegro narre sus años transcurridos en Galicia movido exclusivamente por un mero interés general en hechos en los que encontraba una verdad de carácter social, porque, aunque es cierto, como ya se comentó, que Montenegro reconstruye una realidad en relación a las categorías de clase social, escisión en opresores-oprimidos, distribución económica, instancias ideológicas, aparatos de Estado, etc., no lo es menos que hay una relación conflictiva con su tierra de origen. Y es un síntoma no desdeñable el que repetidamente narre sobre un país del que afirma primero su rechazo. Es posible adelantar la hipótesis de que la relación no es de simple oportunidad o interés ocasional sino que, al contrario, se dibujan perfiles contradictorios que indican una relación compleja.

"CUADERNOS DE ESTUDIOS GALLEGOS", Tomo XLV, Fascículo 110, Santiago 1998 
En las consideraciones con las que suelen comenzar sus cuentos gallegos destaca e insiste en la imposibilidad de borrar de su memoria los hechos vividos durante su infancia en Galicia, hasta el punto de reconocer que son constitutivos de su personalidad. Admite de este modo que su identidad, hasta cierto punto, se encuentra definida por la particularidad de los símbolos que corresponden a la realidad gallega. Y los cuentos se escriben para mostrar el desgarramiento entre dos términos contradictorios, ambos disputándose el espacio de su identidad.

El signo que recorre toda la relación con Galicia es doble. Por un lado, se da una vinculación con este país expresado en la idea de «saudade» que, aunque puede parecer tópica, nos remite inevitablemente a un referente cultural estricto. Recordemos brevemente que Montenegro es contemporáneo de un acontecimiento intelectual decisivo para Galicia como fue la generación Nós y la formación del movimiento nacionalista gallego. El vínculo saudosista se redobla en la expresión de sus relaciones con la naturaleza, también de amplia raigambre en la producción cultural gallega -y portuguesa $-\mathrm{y}$ viene a plantear, al mismo tiempo, la posibilidad de una «mentalidad» de emigrante. A este respecto es preciso reseñar la ambigüedad de Montenegro, porque en su circunstancia personal hay factores que lo aproximan y lo distancian de la figura del emigrante. Esa relación con la tierra de sus orígenes es también fruto, en cierta medida, tanto de una invención como de un hecho concreto, significativo en un autor tan inclinado a apoyarse en las experiencias vividas como razón de una verdadera legitimización artística. Al cabo de los años el autor recupera un vínculo que reivindica como valor dotado de una doble cualidad, tristeza y exaltación.

Sin embargo, junto a esta franca admisión del lazo natal, se encuentra su gesto de ruptura y rechazo, que también es doble puesto que el hecho mismo de experiencias adversas parecen generar una dependencia de signo violento, pero no menos vinculante. Esta posición, no obstante, es complementaria a su identificación con Cuba, si bien para hacer las cosas un poco más difíciles, hay que tener presente el que en los cuentos, y en la vida del autor, la madre del niño protagonista muere y es enterrada en Galicia. Como en la realidad, en la ficción la madre había nacido en Cuba y es la que actúa como referente de esa identidad para el niño. Si en el mundo de ficción se habla de «destino» podemos apuntar que el protagonista-narrador vive cumpliendo el deseo de la madre, vinculándose a Cuba, 
pero al estar sus restos en Galicia, de nuevo vuelve a sentirse reenviado a éste país. Vinculación y desvinculación se entrelazan. Al tiempo que se reclama cubano, reconoce el narrador cómo ese tiempo de la infancia «lo hizo», con un cierto deje determinista que suele brotar aquí y allá en su obra. También como si el sufrimiento y la dureza generasen una relación más callada e íntima. Precisamente hemos apuntado al comienzo la importancia que tuvo su idea de maceración de los individuos a través de experiencias de padecimiento, esfuerzo y dolor.

No obstante, para comprender en toda su significación la ambivalencia de identidad del narrador es preciso no olvidar lo que se comentó a propósito de su análisis de la sociedad gallega y, a partir de ahí, precisar el significado que cobran el padre y la madre en relación a los conceptos de origen e identidad. De esa visión sólo la madre del niño se sustrae de lleno gracias a una religiosidad que se distancia de los dictados de la Iglesia, y que tiene como referencia directa un cristianismo no integrista, desvinculado de la estructura religiosa. Es la actuación de personajes muy concretos los que revelan la estructuración jerárquica del poder local: El cacique y sus familiares, el cura, el maestro que controlan, a su vez, a otras gentes, constituyendo una jerarquía de dominio.

En el cuento «El cordero» esa estructura da cuenta del tipo de relaciones que enlazan a sus componentes: la tía Pepiña, que viene a ser la figura opuesta a la madre, utiliza los regalos, de comida sobre todo, para tener influencia con el cura y el cacique; ella y el maestro se conducen de manera cruel e inflexible. Todos coinciden en su falta de sensibilidad espiritual, no obstante, el rasgo más significativo es el de la desvirtuación de sus señas de identidad: en el maestro son los castigos que niegan su condición de enseñante; en el cura, la tía o el cacique su lujuria taimada, la degradación de lo sexual. Son seres perversos cuyas funciones más propias se han desviado y cuya degradación moral se corrobora en las deformaciones corporales o en los objetos que los acompañan, por ejemplo, el que las disciplinas «monstruosas» descansen en un crucifijo o que la tía, con su moño erecto símbolo de inflexibilidad, haga sacrificar a un cordero por simple crueldad. De ahí lo incongruente que resulta para el niño protagonista el que la «historia sagrada» sea enseñada por un maestro de tales características. Su conducta más identificadora está desvirtuada, no enseña sino que castiga y disfruta con ello, pero en esa conducta reside el signo de lealtad y pertenencia a la estructura de poder local. Por otra parte, las 
costumbres del pueblo tienen un mismo signo negativo. En concreto, el narrador se detiene en apuntar las relaciones amorosas de los habitantes, marcadas por el irracionalismo de creencias supersticiosas, manipuladas por una vieja «bruja». Es la otra cara de esa religión integrista que arrastra consigo la ignorancia de las gentes que también han acabado por aceptar una conducta moral condenable .

Los personajes de la madre y el padre poseen un interés especial, ambos entran en relaciones complejas con la estructura social. Para comprender satisfactoriamente la figura materna es preciso recuperar la dicotomía naturaleza y sociedad. Como acabamos de ver, la primera se encuentra completamente deshecha en el ámbito de lo social, cuyos miembros se hallan literalmente desnaturalizados. En las reflexiones iniciales de «El cordero», el narrador había establecido, en términos más generales, esta diferencia que se concretiza más tarde en la acción. La naturaleza como principio de realidades y cualidades originales, pura y bella -expresado particularmente en las consideraciones paisajísticas- se vincula a la madre. Es decir, el valor espiritual y estético que se otorga a los paisajes gallegos se conecta con la figura materna, pero bien sintomático es que esa atribución se realice mediante la elaboración reflexiva del narrador o a través de la ensoñadora del niño protagonista, estableciendo siempre, de este modo, un corte respecto a la realidad concreta de la acción del cuento.

Efectivamente, es importante reparar en el hecho de que esta ecuación entre madre y naturaleza se establece, sobre todo, en las ensoñaciones del niño, aunque el narrador las articule de manera particular. Y es que el gesto infantil es el de situar a la madre en un imaginario liberado del medio social agobiante. Por eso podemos comprender que el personaje infantil se refugie en el medio natural, para defenderse de manera inmediata de la agresividad social, pero, más decisivamente, para fundir las dos tierras de origen. Lo significativo es que la ensoñación también caracteriza a la madre, cuyo gesto identificador es la mirada perdida en el horizonte, anhelando la vuelta a su tierra caribeña. El hijo ve en ella una circunstancia común por su similar situación de división entre dos países, por sus dificultades de adaptación al medio rural gallego y de diferencias con la familia paterna; de todo esto nace una dicotomía entre madre $=$ naturale $z a=$ bondad $e$ ilusiones y familia paterna $=$ medio social $=$ maldad.

"CUADERNOS DE ESTUDIOS GALLEGOS", Tomo XLV, Fascículo 110, Santiago 1998. 
En este punto hay que destacar el que la condición ensoñadora armonice imagen materna, país ideal y códigos representativos religiosos. En «El cordero» la identificación madre/país dador de identidad se formula en una serie de escenarios imaginados de acuerdo con la iconografía bíblica. En un espacio de clima suave se ensueñan figuras femeninas de elevada espiritualidad y de delicada sensualidad: «Mujeres bellas, dulces, rítmicas. Mujeres descalzas que vestían claros hábitos». Es una imaginería candorosa de un supuesto tiempo primitivo del cristianismo, anterior a toda escisión, que funciona en el texto para evocar un tiempo primero del mundo, y que aparece literaturizado y mitificado, de acuerdo con convenciones muy estrictas. Pero es inevitable reconocer que aquí la figura materna viene a representar un principio de religiosidad diferente, que se nos da no sólo desde la óptica infantil, también se hace desde otros participantes de la acción, y que remacha la confrontación radical con el medio aldeano. En particular la primera se opone a la tía Josefa. El choque se concretiza en la diferente manera de vestir, entre el atuendo delicado de la primera «tan distinto de aquellos llenos de colorines que usaban las aldeanas de mi pueblo»; en el rechazo a confesar con el cura por ser un «lebertino»; en el hecho de colgar una hamaca en el jardín ante el escándalo de la tía; o, por otra parte, la relación que se establece con el cordero por el mismo origen bíblico del animal, en oposición a los representativos de la aldea, perro o gato, con sus significados adosados de violencia, crueldad e insidia.

Así pues, la madre remite a otro país y causa un doble enfoque, suscita la cuestión de un doble origen. El país con el que se identifica el niño es uno lejano e inventado en relación con la madre, pero también en esa invención se incluye la representación de lo más auténtico del otro país, Galicia, el del padre. Por tanto, en ambos casos es un país que percibe como ausente y que sólo se constituye por la invención. Los cuentos se escriben desde la perspectiva de un narrador adulto desde Cuba que piensa Galicia y en la acción actúa la del niño en sentido inverso. Cuando se produzca la muerte de la madre, este ambiguo país natal acentúa su significado contradictorio: ella simboliza una tierra lejana y promisoria, pero está enterrada en ese viejo país.

A su vez, la figura del padre encarna la otra identidad, con otros referentes contradictorios para el niño. No deja de ser igualmente compleja por una misma razón de ambigüedad, resultado de la postura paterna respecto a ciertas funciones sociales. El padre se identifica con la sociedad gallega, 
de hecho, pertenece a ella por ser un representante del poder local, con todo lo que esto significa para el héroe infantil. Por lo demás, es evidente que la figura del poderoso quedó muy grabada en la conciencia de Montenegro como lo demuestran los términos de la relación de los personajes infantiles con sus padres o de otros personajes con el detentador del poder, como, por ejemplo, se constata en el cuento «La huella del cacique» en el que atracción y distanciamiento resultan muy claras. Para el niño la conducta paterna, tanto en lo privado como en lo público, representa la autoridad, incontrolable, a veces arbitraria, y, por lo mismo, fuente de temor, lo que se manifiesta en una relación muy pensada en sus estrategias y que genera una dificultad interior, además de un conflicto de identificación con gentes de otras clases sociales, cuando el padre actúa como miembro del grupo social que el protagonista infantil percibe como opresor.

La imagen del padre por esto resulta mucho más elusiva pero no carente de importancia. En el cuento «La escopeta» la figura paterna, a diferencia de otros ejemplos en que está casi siempre ausente, se encuentra muy presente y dibujándose con gestos afirmativos. Aquí el niño lo necesita para afirmarse. Significativamente entra en la acción mediante una ensoñación del hijo, en ella imagina una escena compensatoria en la que su progenitor lo elogia y lo nombra su sucesor. No obstante, éste menciona en la conversación que tendrán que volver a Cuba porque su esposa quiere retornar allí. El protagonista infantil, entonces, descubre que la situación de esa persona tan próxima y tan inasible puede ser también la de alguien separado de su tierra, precisamente de alguien a quien él relaciona tanto con ella. En la siguiente secuencia el hijo actúa generosamente para salvar la vida de un pájaro, acto que él identifica como propio de su madre. Lo ha hecho inconscientemente por ser como ella, sólo que inmediatamente se da cuenta del verdadero significado y de que para el padre, por el contrario, será condenable. Imagina a continuación una segunda escena que es el reverso de la anterior. Ahora el padre lo castiga y el cura, con el que estaba hablando, también lo juzga severamente. Ser como la madre no es compatible con ser como el padre. Esta escisión no es exterior a los conflictos de identidad del autor. El desenlace del cuento muestra lo irresoluble del conflicto: el niño arrastrará una marca en la imposibilidad de encontrar una armonización. Vivirá su doble origen o la dificultad de su doble lealtad como una contradicción. De esa contradicción nacerá su madurez.

"CUADERNOS DE ESTUdIOS GALLEGOS", Tomo XLV, Fascículo 110, Santiago 1998. 
«La patria es lo que se pierde» decía Hölderlin, «Tenemos una patria pero para perderla», ha dicho más recientemente Sibony. Podemos concluir, entonces, que en Montenegro no se plantea la cuestión de la patria como aquello que se tiene sólo para perderse (es decir, exigencia de que la patria debe inventarse a cada paso), sino que se vive en una relación, todo lo contradictoria que se quiera, pero definida por la aceptación y por el rechazo, por la nostalgia y por el sufrimiento, a partir del concepto de vínculo. 